\title{
A Survey in the Basal Like Breast Carcinoma Phenotype in North East of Iran
}

\author{
Roham Salek, ${ }^{1}$ Fatemeh Varshoee Tabrizi, ${ }^{2}$ Kamran Ghaffarzadegan, ${ }^{3}$ Golnaz Sabouri, ${ }^{4}$ and Azar \\ Fanipakdel ${ }^{1, *}$ \\ ${ }^{1}$ Cancer Research Center, Faculty of Medicine, Mashhad University of Medical Sciences, Mashhad, Iran \\ ${ }^{2}$ Reza Radiation Oncology Center, Mashhad, Iran \\ ${ }^{3}$ Pathology Department, Razavi Hospital, Mashhad, Iran \\ ${ }^{4}$ Clinical Governance Department, Mashhad University of Medical Sciences, Mashhad, Iran \\ "Corresponding author: Azar Fanipakdel, Cancer Research Center, Faculty of Medicine, Mashhad University of Medical Sciences, Mashhad, Iran. Tel: +98-5138461518, E-mail: \\ fanipa@mums.ac.ir
}

Received 2015 November 14; Revised 2016 February 01; Accepted 2017 January 03.

\begin{abstract}
Background: Breast carcinoma is not a homogenous disease. It is divided into 5 pathological subtypes of luminal1, luminal2, strongly Her2 positive, basal like, and normal breast like. Basal like breast carcinoma that accounts for about $15 \%$ of all breast cancers has an aggressive clinical behavior with the features of high nuclear grade, negative estrogen receptor, progesterone receptor, and Her2 reactivity (triple negative).

Objectives: We aimed at identifying the prevalence of basaloid phenotype among triple negative (TN) cases in our region via immunohistochemistry (IHC) staining using basaloid markers.

Methods: We reviewed breast cancer patients in Omid and Imam Reza hospitals, Mashhad, Iran, between 2003 and 2007. We obtained the paraffin blocks from TN cases for immune-staining using cytokeratin 5/6 (CK5/6), cytokeratin 14 (CK14) and epidermal growth factor receptor1 (EGFR1) markers.

Results: The incidence of TN disease among breast cancers was 21\% (156/747). Based on IHC reactivity with at least one of the basaloid markers, from 59 available samples, 44 (75.4\%) were basaloid.

Conclusions: In our region, most triple negative tumors were basal like breast cancer (BLBC). Among these cases, most immunereactivity was observed for EGFR1, followed by CK14 and CK5/6.
\end{abstract}

Keywords: Breast Cancer, Basal Like, Triple Negative, Immunohistochemistry, Cytokeratin 5/6, Cytokeratin 14, EGFR1

\section{Background}

Breast cancer ranking first among female cancers (1), comprises $24.4 \%$ of all malignancies in women (2). Based on the international agency of research on cancer (IARC) reports (Golobocan-2008), the age standardized incidence and mortality rates of breast cancer in Iranian females were 18.4 and 8.9 per 100.000, respectively (3).

Sharifian et al. analyzed the national incidence data from the Iranian annual national cancer registration reports from 2003 to 2009 and national death statistics reported by the ministry of health and medical education from 1995 to 2010, stratified by age group. They showed that the general mortality rate of breast cancer has increased during these years from 0.96 to 4.33 per 100,000 and the incidence rate increased from 16.0 to 28.3 per 100,000 for the years under study, concluding that the burden of breast cancer for Iranian women is still increasing (4).

Breast cancer is a heterogeneous disease. According to the new classification, breast carcinomas are classified into five diverse subgroups as luminal A, luminal B, strongly Her2 positive, Basal like, and normal breast Like (5).

Basal like breast cancer (BLBC) is a specific clinical and pathological entity which consists of about $15 \%$ of breast cancers in western countries. However, according to some reports, basal-like cancer accounts for from $8 \%$ up to $37 \%$ of all breast cancers, mostly depending on the proportion of grade 3 breast cancers in their population $(6,7)$.

As it is generally accepted, BLBC is defined by high histological grade, predominantly triple-negativity (negative for ER, PR and Her2 receptors), basal cytokeratins expression, and a more aggressive clinical course and generally poor prognosis (8).

Almost $80 \%$ of triple negative breast cancers are basal like breast cancers. This phenotype is more common in premenopausal patients. Fifty percent of these tumors show over expression of EGFR which itself is a marker of metaplastic basal like breast cancer and an indicator of aggressive behavior. The outcome of these patients is ap- 
proximately similar to ER-negative Her2-strongly positive patients. However, trastuzumab is not recommended in these cases $(9,10)$.

BLBC may be recognized by IHC, real-time reverse transcriptase polymerase chain reaction-based signatures (RTPCR) or gene expression profile (GEP) methods, the latter is the gold standard for identification of BLBC. GEP is very costly and is not used in routine clinical assessments. Although RT-PCR has had a concordance rate of more than $90 \%$ with microarray based analysis, only one IHC panel has been validated by expression arrays. This panel which is comprised of ER, HER2, ck5/6 and EGFR identifies BLBC tumors with a sensitivity of $76 \%$ and specificity of $100 \%$. The use of this immunohistochemical panel has the potential to identify a morphologic spectrum of basal-like cancer, which includes grade III invasive ductal carcinomas, atypical medullary carcinomas, and metaplastic breast cancers $(10,11)$.

There is still no consensus agreement on which method is proper to identify BLBC. Most authors defined BLBCs using IHC, mainly CK5 or CK5/6 reactivity in their methods. Other markers, such as CK14, CK17, EGFR, CKit, P63, P-cadherin and SMA, were also utilized $(10,11)$.

\section{Objectives}

The main objective of this study is to determine the prevalence rate of basaloid phenotype among triple negative breast cancers in our geographic region via immunohistochemistry staining for CK5, CK14 and EGFR markers and explore the criteria that can be used to identify these tumors in the routine practice.

\section{Methods}

We found and reviewed the documents of breast cancer patients in 2 oncology centers of Omid and Emam Reza hospitals, affiliated to Mashhad University of Medical Sciences, Mashhad, Iran, between the years 2003 and 2007. The pathological reports were searched and only those with available all basic IHC assessments (ER, PR and HER2) were included. The following criteria were selected to consider a tumor into triple negative phenotype: ER and PR were defined as negative if immunoperoxidase staining of tumor cell nuclei was less than $5 \%$ and Her2 was considered negative if IHC score was 0 or $1+$. We did not encompass Her-2 moderately positive (2+), considering the requirement for negative confirmation by FISH or cytogenetic methods.

We also recorded some of demographic characteristics of the patients including age, menopausal status, histological grade of tumors (based on Bloom-Richardson grading system) and some other clinical parameters. We also repeated immune-staining for some samples for ER, PR and HER2 reactivity randomly to find if there was any discordance between original reports of triple negativity and our findings. The available samples were immunostained for basaloid markers reactivity including cytokeratin 5/6, cytokeratin 14 and EGFR proteins.

\subsection{Immunohistochemistry}

We collected the paraffin blocks of all the patients' biopsies, sliced and colored them with hematoxylleneosin. All the slides were checked by a pathologist and marked. We provided $2 \mu$ cuts from the slides. After 24 hours, they were ready for immunohistochemical staining.

At the first step, all the slides were hydrated and deparaffinated with xylon and alcohol and demaskated by EDTA-TRIS solution $(\mathrm{PH}=7)$. After washing the slides with TBS (Biogene co) all of them were incubated with $\mathrm{H} 2 \mathrm{O} 2$ and protein block (Novocastra co), and CD14 (code RTU LLO02 Novocastra co), according to the markers type, for $30 \mathrm{~min}$ utes. Then, the slides were incubated first by post primary block and then by polymer novoline for 30 minutes (Novolink detection system REF RE7280-K). All slides were colored with chromogen DAB (Novolink detection system REF RE7280-k) and hematoxyllen. The pathologist reviewed all the slides which were dehydrated, cleaned and labeled.

The coloring method was cytoplasmic for ck5/6 and ck14 and membranous for EGFR. The reactive cell percentiles were measured as color percentage and color intensity varied between $0,+1,+2$ and +3 (negative, weak, moderate and strong).

\section{Results}

Among 978 breast cancer cases referred to our centers during the five-year period, 231 patients were excluded due to inadequate information regarding immunohistochemistry results. From 747 remaining patients, 156 cases were ER, PR and HER2 negative. Therefore, the prevalence rate of the triple negative tumors among our study group was $21 \%$ (156/747). The mean age of these triple negative patients was 48.4 year $( \pm 0.997)$. Postmenopouse patients accounted for $47.9 \%$ of those with known menopausal status. Family history of cancer was recorded in $27.1 \%$. Among 85 patients with a known tumor grade, $58.9 \%$ were grade 3 , followed by grade 2 (37.6\%) and grade 1 (3.5\%). The most prevalent histological morphologies were ductal and lobular (81\%, 11.7\%). Women with triple negative breast cancers were slightly younger (Mean: 48 years vs. 51 years, $\mathrm{P}=0.105$, t-test), more probably premenopausal (52\% vs. $47.9 \%$ : $\mathrm{P}=0$. 
22), and had more commonly dedifferentiated tumors (81\% vs. $19 \%: \mathrm{P}=0.000)$. The demographic characteristics of the 156 cases with triple negative features are illustrated in Table 1.

\begin{tabular}{|c|c|c|}
\hline Characteristics & No of Patients & $\%$ \\
\hline Total enrolled & 156 & 100 \\
\hline \multicolumn{3}{|l|}{ Age (years) } \\
\hline Median (Range) & $47.5(25-79)$ & \\
\hline Mean \pm SEM & $48.4 \pm 0.997$ & \\
\hline \multicolumn{3}{|l|}{ Menopausal Status } \\
\hline Premenopouse & 61 & 52 \\
\hline Postmenopouse & 56 & 47.9 \\
\hline Unknown & 39 & \\
\hline \multicolumn{3}{|l|}{ Familial history of cancer } \\
\hline No & 70 & 72.9 \\
\hline Yes & 26 & 27.1 \\
\hline Unknown & 60 & \\
\hline \multicolumn{3}{|l|}{ Histologic Grade } \\
\hline Grade 1 & 3 & 3.5 \\
\hline Grade 2 & 32 & 37.6 \\
\hline Grade 3 & 50 & 58.9 \\
\hline Unknown & 71 & \\
\hline \multicolumn{3}{|l|}{ Histologic Morphology } \\
\hline Ductal & 111 & 81 \\
\hline Medullary & 16 & 11.7 \\
\hline Lobular & 4 & $2.9 \%$ \\
\hline Papillary & 4 & 2.9 \\
\hline Sacomatoid & 1 & 0.7 \\
\hline Metaplastic & 1 & 0.7 \\
\hline Unknown & 19 & \\
\hline
\end{tabular}

We could retrieve 63 paraffin blocks of triple negative patients from which, 59 samples were proper for immunostaining. Random staining of 15 samples for ER, PR and HER2 did not show any discordance with the original pathological reports. According to our definition, 44 cases were basal like breast carcinomas. Therefore, prevalence rates of BLBC phenotype among our triple negative group and the whole study group was $74.5 \%$ and $15.6 \%$, respectively. Among antibodies we used, EGFR turned positive the most (34 patients, 57.6\%), followed by CK14 (19 patients, $32.2 \%$ ) and $\mathrm{CK} 5 / 6$ (10 patients, $17 \%$ ).

The frequencies of 4 different situations of immunos- taining among cytogenetic markers in the study are illustrated in Tables 2 and 3.

\section{Discussion}

In this retrospective study consisting of 747 invasive breast cancers, $21 \%$ were triple negative. We assessed 59 proper and available triple negative samples using three basaloid IHC markers (EGFR, CK5/6, CK14) and observed the immuno-reactivity by at least one of these markers in $74 \%$ of cases, indicating a significant concordance between TNTs and BLBCs.

According to previous studies, triple negative tumors account for $6.8 \%$ to $31.7 \%$ of all breast cancers $(12,13)$. Compared to other breast cancer patients, the average age of this group is lower and includes more pre-menopause cases (14-19). However, one study by Iwase reported that triple negative patients were more frequently postmenopausal (16). Numerous studies indicated that in comparison with other cases, pathological grade of TNTs were higher (13, 17, 20-23) and Ki67 over expression was more common $(8,9,14,20,21)$. In a retrospective cohort study on Korean breast cancer society registration program data, TNBC patients showed higher tumor size, lymphatic stage, histological grade, and more lymphovascular invasion. However, in multivariate analysis, only histological grade and Ki67 were significantly higher. Although TNTs are a heterogenic group of tumors. They are mostly originated from myoepithelial cells (24). This can be shown by cytogenetic studies or IHC methods; the former is more accurate, while the latter is simpler, less expensive, and more accessible.

GEP is the gold standard for the identification of basallike breast cancer. However, the use of microarrays is expensive, largely limited to fresh or frozen samples, and difficult to use in the routine diagnostic practice. CK5 (or $\mathrm{CK} 5 / 6)$ is probably the most frequently used basal CK, either alone or in combination with CK14, CK17, or both (6). Nielsen et al. reported that $62 \%(13 / 21)$ of basal-like tumors express CK5/6 (10). Livasy et al. demonstrated that $61 \%(11 / 18)$ of basal-like tumors express CK5/6 (23). Several groups have tried to define surrogate IHC markers to identify the molecular subgroups classified based on microarray expression analysis. The immunohistochemical panel comprised of 4 markers (ER, HER2, CK5/6, and epidermal growth factor receptor [EGFR]) has been validated by expression arrays and identifies basal-like cancers with $100 \%$ specificity and $76 \%$ sensitivity (10). However, this definition is not complete and has some limitations. Another approach to identify basal-like breast cancer is using triple-negative phenotype, considering that 
Table 2. Basal Marker Expression of Each of Three Antibodies in 59 TNT Tumors

\begin{tabular}{|c|c|c|c|}
\hline & EGFR(\%) & CK5/6 (\%) & Ck14 (\%) \\
\hline Negative & $25(42.4)$ & $49(83)$ & $40(68)$ \\
\hline Weakly positive & $11(18.6)$ & $5(8.5)$ & $8(13.5)$ \\
\hline Moderately positive & $11(18.6)$ & $4(6.8)$ & $7(11.8)$ \\
\hline Strongly positive & $12(20.3)$ & $1(1.7)$ & $4(6.8)$ \\
\hline
\end{tabular}

Table 3. Basal Marker Expression of Each of Three Antibodies in 44 BLB Tumors

\begin{tabular}{|c|c|c|c|}
\hline & EGFR(\%) & CK5/6 (\%) & Ck14 (\%) \\
\hline Negative & $10(22.7)$ & $34(77.2)$ & $25(56.8)$ \\
\hline Weakly positive & $11(25)$ & $5(11.3)$ & $8(18.2)$ \\
\hline Moderately positive & $11(25)$ & $4(9.1)$ & $7(16)$ \\
\hline Strongly positive & $12(27.2)$ & $1(2.3)$ & $4(9.1)$ \\
\hline Overall positive & $34(77.2)$ & $10(22.7)$ & $19(43.2)$ \\
\hline
\end{tabular}

most basal-like breast cancers are ER, PR, and HER-2 negative (the triple-negative phenotype) (10). The most practical definition of basal-like tumors is based on hormone receptors, HER2 negativity, and specific basal marker positivity (CK5/6, CK14, CK17, and EGFR) (10,11).

Nielsen et al. added PR negativity to this definition. Based on this new definition, basal-like breast cancers are defined as ER, PR, and HER2 negative breast cancers that express CK5/6 and/or EGFR $(10,25)$.

Some authors believe that the addition of CK14 to this panel can improve the definition of basal-like cancer (6 markers: ER-negative, PR-negative, HER2-negative, and CK5/6-positive and/or CK14-positive and/or EGFR-positive tumors) for the following reasons: 1- CK14 is expressed in basal/myoepithelial cells of the breast and forms complexes with $\mathrm{CK} 5$; 2 - it has a staining pattern that is more reliable than that of CK17; 3- it stains a proportion of breast cancer cases that overlap with $\mathrm{CK} 5 / 6$ positivity; and 4 - it is associated with a poor outcome.

Regarding this, we used 3 markers, EGFR1, CK5/6, and CK14, which turned positive in $44 \%, 17 \%$ and $32 \%$ of TNTs, respectively (overall $74.5 \%$, or 44 tumors out of 59 TNTs). According to previous studies, between $50 \%$ to $80 \%$ of triplenegative tumors express basal markers $(18,25)$. This subgroup of tumors is associated with poor outcome $(11,25)$. Our result approximated the upper limit of this range which could be due to the use of six markers in our study.

The sensitivity of each basal marker among the BLBC group was $77.2 \%$ for EGFR (34 out of 44 ), 43.2\% for CK14 (19 out of 44 ) and $22.7 \%$ for CK5/6 (10 out of 44 ).
Some investigators have used P-cadherin (26), c-Kit (27), nestin (28), osteonectin (29), vimentin, and laminin (30, 31) to improve basal-like cancer detection. However, not all TNTs are IHC positive, because, according to GEP analysis, not all TNTs are basaloid. On the other hand, in case of IHC study of non-TNT by basaloid markers, a small percent of them are reported as positive, addressing that TNTs and basaloid cancers do not have a 100\% concordance (32).

Defining the basal cell breast cancers helped us to recognize the wide spectrum of morphologies including invasive ductal carcinoma grade III, metaplastic morphologies such as spindle cell, osteoid and chonroid metaplasia, SCC, and apocrine morphology, which are more common in basaloid tumors $(33,34)$. In our study, we found a 46 years old triple negative metapelastic breast cancer patient. In IHC, her tumor was strongly positive for CK14 and moderately positive for EGFR, but negative for CK5/6. She found a brain metastasis by the metapelastic breast cancer with osteosarcomatose differentiation and passed away in less than one year from diagnosis. Gwin reports a series of 21 metapelastic breast cancers with chondroid differentiation that were all triple negative, with no expression of androgen receptors. Nine out of 21 cases had grade II or III DCIS. Ten cases had a very aggressive course of disease, with visceral and chest wall metastases, which led to death in 3 patients. Lymphadenopathy was very common, $60 \%$ of which had chondroid differentiation, too. EGFR1 was positive in $88 \%$, consistent in the proposed basaloid phenotype for all metapelastic cancers (18).

Expectedly, like every other study, this one was not 
without limitations. First, it was a retrospective study. Second, pathology reports and histological grading were done in different laboratories without a central review. Third, blocks were from different laboratories and different cities, and some of them lacked enough tumor or had lost quality to perform basal cell IHC on them; therefore, we could exam the paraffin blocks of only 38\% (59 out of 156) of TN patient for basaloid IHC. However, our trial had advantages too. First, it contained the adequate number of breast cancer patients. Secondly, triple negativity was double checked by an expert pathologist. Third, basaloid specific IHC of all samples were performed in a central lab and reviewed by the same pathologist. Fourth, we used three specific IHC markers (overall: six markers) to enhance the sensitivity of our test; and fifth, it shows the unfavorable histological grade in TN tumors.

In conclusion, triple negative breast cancer tumors make a considerable group of breast cancers mainly from basaloid phenotype and may have de-differentiated and metaplastic features. Using different IHC markers enhances the sensitivity to detect BLBCs. This entity makes a specific subgroup of breast cancer with its specific biology, oncogenesis and clinical course. Paying attention to this specific category, the clinician may take advantage of specific treatments in the future.

\subsection{Conclusion}

The great majority- but not all - of TNTs are BLBC. In our study, the most immunopositivity in IHC staining was observed by EGFR1, followed by CK14 and CK5/6. Screening for basaloid breast cancer in TNTs may be useful in deciding for therapeutic strategy.

\section{Acknowledgments}

This study was supported by Research Deputy of Mashhad University of Medical Sciences. The authors would like to thank the collaboration of compassionate personal of Dr. Moayyed pathology laboratory of Mashhad.

\section{Footnotes}

Authors' Contribution: Roham Salek and Azar Fanipakdel have designed the present study; Roham Salek, Fatemeh Varshoee Tabrizi, Kamran Ghaffarzadegan, and Azar Fanipakdel have written the article; Roham Salek and Azar Fanipakdel have edited the article; Fatemeh Varshoee Tabrizi, Kamran Ghaffarzadegan, Golnaz Sabouri and Azar Fanipakdel have been responsible for collecting the data; Roham Salek, Kamran Ghaffarzadegan, and Azar Fanipakdel have contributed to the analysis and data interpretation.
Conflicts of Interest: There is no conflict of interest in this article.

Financial Disclosure: None declared.

\section{References}

1. WHO. . Iranian annual of national cancer registration report, 20052006. WHO.;

2. Ferlay J, Shin HR, Bray F. Cancer incidence and mortality worldwide, international agency for research on cancer. Lyon: Globocan; 2010.

3. Sadjadi A, Nouraie M, Ghorbani A, Alimohammadian M, Malekzadeh R. Epidemiology of breast cancer in the Islamic Republic of Iran: first results from a population-based cancer registry. East Mediterr Health J. 2009;15(6):1426-31. [PubMed: 20218134].

4. Sharifian A, Pourhoseingholi MA, Emadedin M, Rostami Nejad M, Ashtari S, Hajizadeh N, et al. Burden of Breast Cancer in Iranian Women is Increasing. Asian Pac J Cancer Prev. 2015;16(12):5049-52. [PubMed: 26163639].

5. Gianni B, Gabriel NH, Pinuccia V. Textbook of breast cancer aclinical guide to therapy. 3 ed. ; 2006. p. 86.

6. Huo D, Ikpatt F, Khramtsov A, Dangou JM, Nanda R, Dignam J, et al. Population differences in breast cancer: survey in indigenous African women reveals over-representation of triple-negative breast cancer.JClin Oncol. 2009;27(27):4515-21. doi:10.1200/JCO.2008.19.6873. [PubMed: 19704069].

7. Rakha E, Reis-Filho JS. Basal-like breast carcinoma: from expression profiling to routine practice. Arch Pathol Lab Med. 2009;133(6):860-8. doi: 10.1043/1543-2165-133.6.860. [PubMed: 19492878].

8. Katrina RB, Monica B, Rosemary DC, Carol AP, Vincent C. Descriptive analysis of estrogen receptor (er)- negative, progesterone receptor (pr)-negative, and her2- negative invasive breast cancer, the so-called triple-negative phenotype. Cancer. 2007.

9. Francesca R, Sandra B, Amalia F, Angelo M, Camilla C, Romeo B, et al. Triple-negative breast cancer:current state of the art. Tumori. 2010;96:875-88.

10. Nielsen TO. Immunohistochemical and clinical characterization of basal- like subtype of invasive breast carcinoma. Clinical Cancer Res. 2004:5367-74.

11. Rakha EA, Reis-Filho JS, Ellis IO. Basal-like breast cancer: a critical review. J Clin Oncol. 2008;26(15):2568-81. doi: 10.1200/JCO.2007.13.1748. [PubMed: 18487574].

12. Rubovszky G, Udvarhelyi N, Horvath Z, Lang I, Kasler M. [Triplenegative breast carcinoma-rewiev of current literature]. Magy Onkol. 2010;54(4):325-35. doi: 10.1556/MOnkol.54.2010.4.6. [PubMed: 21163763].

13. Nishimura R, Arima N. Is triple negative a prognostic factor in breast cancer?. Breast Cancer. 2008;15(4):303-8. doi: 10.1007/s12282-0080042-3. [PubMed: 18369692].

14. Mise M, Higashide S, Hashimoto K, Kawada K, Hanaki K, Kanda Y, et al. [Clinicopathological features of young patients with triple negative breast cancer]. Gan To Kagaku Ryoho. 2009;36(10):1677-81. [PubMed: 19838027].

15. Gerson R, Alban F, Villalobos A, Serrano A. [Recurrence and survival rates among early breast cancer cases with triple negative immunophenotype]. Gac Med Mex. 2008;144(1):27-34. [PubMed: 18619055].

16. Lund MJ, Trivers KF, Porter PL, Coates RJ, Leyland-Jones B, Brawley OW, et al. Race and triple negative threats to breast cancer survival: a population-based study in Atlanta, GA. Breast Cancer Res Treat. 2009;113(2):357-70. doi: 10.1007/s10549-008-9926-3. [PubMed: 18324472].

17. Lee JA, Kim KI, Bae JW, Jung YH, An H, Lee ES, et al. Triple negative breast cancer in Korea-distinct biology with different impact of prog- 
nostic factors on survival. Breast Cancer Res Treat. 2010;123(1):177-87. doi: 10.1007/s10549-010-0998-5. [PubMed: 20574671].

18. Diaz LK, Cryns VL, Symmans WF, Sneige N. Triple negative breast carcinoma and the basal phenotype: from expression profiling to clinical practice. Adv Anat Pathol. 2007;14(6):419-30. doi: 10.1097/PAP.0b013e3181594733. [PubMed: 18049131].

19. Carotenuto P, Roma C, Rachiglio AM, Botti G, D’Alessio A, Normanno $\mathrm{N}$. Triple negative breast cancer: from molecular portrait to therapeutic intervention. Crit Rev Eukaryot Gene Expr. 2010;20(1):17-34. [PubMed: 20528735].

20. Lee JH, Kim SH, Suh YJ, Shim BY, Kim HK. Predictors of axillary lymph node metastases (ALNM) in a Korean population with T1-2 breast carcinoma: triple negative breast cancer has a high incidence of ALNM irrespective of the tumor size. Cancer Res Treat. 2010;42(1):30-6. doi: 10.4143/crt.2010.42.1.30. [PubMed: 20369049].

21. Koo JS, Jung W. Clinicopathlogic and immunohistochemical characteristics of triple negative invasive lobular carcinoma. Yonsei Med J. 2011;52(1):89-97. doi: 10.3349/ymj.2011.52.1.89. [PubMed: 21155040].

22. Reis-Filho JS, Tutt AN. Triple negative tumours: a critical review. Histopathology. 2008;52(1):108-18. doi: 10.1111/j.13652559.2007.02889.x. [PubMed: 18171422].

23. Livasy CA, Karaca G, Nanda R, Tretiakova MS, Olopade OI, Moore DT, et al. Phenotypic evaluation of the basal-like subtype of invasive breast carcinoma. Mod Pathol. 2006;19(2):264-71. doi: 10.1038/modpathol.3800528. [PubMed: 16341146].

24. Tischkowitz M, Brunet JS, Begin LR, Huntsman DG, Cheang MC, Akslen LA, et al. Use of immunohistochemical markers can refine prognosis in triple negative breast cancer. BMC Cancer. 2007;7:134. doi: 10.1186/1471-2407-7-134. [PubMed: 17650314].

25. Cheang MC, Voduc D, Bajdik C, Leung S, McKinney S, Chia SK, et al. Basal-like breast cancer defined by five biomarkers has superior prognostic value than triple-negative phenotype. Clin Cancer Res. 2008;14(5):1368-76. doi: 10.1158/1078-0432.CCR-07-1658. [PubMed: 18316557].

26. Matos I, Dufloth R, Alvarenga M, Zeferino LC, Schmitt F. p63, cytokeratin 5, and P-cadherin: three molecular markers to distinguish basal phenotype in breast carcinomas. Virchows Arch. 2005;447(4):688-94. doi: 10.1007/s00428-005-0010-7. [PubMed: 16012853].

27. Kim MJ, Ro JY, Ahn SH, Kim HH, Kim SB, Gong G. Clinicopathologic significance of the basal-like subtype of breast cancer: a comparison with hormone receptor and Her2/neu-overexpressing phenotypes. Hum Pathol. 2006;37(9):1217-26. doi: 10.1016/j.humpath.2006.04.015. [PubMed: 16938528].

28. Li H, Cherukuri P, Li N, Cowling V, Spinella M, Cole M, et al. Nestin is expressed in the basal/myoepithelial layer of the mammary gland and is a selective marker of basal epithelial breast tumors. Cancer Res. 2007;67(2):501-10. doi: 10.1158/0008-5472.CAN-05-4571. [PubMed: 17234757].

29. Lakhani SR, Reis-Filho JS, Fulford L, Penault-Llorca F, van der Vijver M, Parry S, et al. Prediction of BRCA1 status in patients with breast cancer using estrogen receptor and basal phenotype. Clin Cancer Res. 2005;11(14):5175-80. doi: 10.1158/1078-0432.CCR-04-2424. [PubMed: 16033833].

30. Koronakis N, Karanikas G, Lagoudianakis EE, Grosomanidis D, Pappas A, Chrysikos J, et al. Analysis of clinical and molecular associations of triple negative breast cancers in node-negative patients. Eur J Gynaecol Oncol. 2010;31(3):304-7. [PubMed: 21077474].

31. Rodriguez-Pinilla SM, Sarrio D, Honrado E, Moreno-Bueno G, Hardisson D, Calero F, et al. Vimentin and laminin expression is associated with basal-like phenotype in both sporadic and BRCA1associated breast carcinomas. J Clin Pathol. 2007;60(9):1006-12. doi: 10.1136/jcp.2006.042143. [PubMed: 17105822].

32. Foulkes WD, Smith IE, Reis-Filho JS. Triple-negative breast cancer. N Engl J Med. 2010;363(20):1938-48. doi: 10.1056/NEJMra1001389. [PubMed: 21067385].

33. Kaplan HG, Malmgren JA. Impact of triple negative phenotype on breast cancer prognosis. Breast J. 2008;14(5):456-63. doi: 10.1111/j.15244741.2008.00622.x. [PubMed: 18657139].

34. Bouchalova K, Cizkova M, Cwiertka K, Trojanec R, Hajduch M. Triple negative breast cancer-current status and prospective targeted treatment based on HER1 (EGFR), TOP2A and C-MYC gene assessment Biomed Pap Med Fac Univ Palacky Olomouc Czech Repub. 2009;153(1):137. [PubMed: 19365520]. 